\title{
MAX WEBER E O ESTADO RACIONAL MODERNO*
}

\author{
Marcos Augusto Maliska**
}

\begin{abstract}
RESUMO
O presente texto é uma pequena revisão do pensamento de Max Weber sobre o Estado Moderno. Se o desenvolvimento das instituições sociais, econômicas e culturais, nas sociedades ocidentais modernas, foi desencadeado por um processo geral de racionalização, o núcleo organizativo do Estado Moderno caracteriza-se, entre outros aspectos, por meio da introdução de um central e contínuo sistema tributário, um central comando militar, pelo monopólio do uso da violência e por uma administração burocrática. O presente texto não investiga as implicações que o pensamento de Weber tem para os Estados abertos do século XXI, mas ele foi escrito com o objetivo de se compreender o Estado Moderno e os seus desafios no século XXI.

Palavras-chave: Estado Racional; burocracia; legitimidade do poder; carisma; Estado aberto.
\end{abstract}

\begin{abstract}
Sumário: 1 INTRODUÇÃO; 2 O ESTADO RACIONAL; 3 AS TRÊS FORMAS DE LEGITIMAÇÃo DO PODER; 4 A BUROCRACIA; 5 REFERÊNCIAS.
\end{abstract}

* Capítulo 4 da Primeira Parte da Tese de Doutorado Os desafios do Estado Moderno. Federalismo e integração regional, defendida junto ao Programa de Pós-Graduação em Direito Doutorado da UFPR.

** Bacharel em Direito pela UFSC (1997), Procurador Federal (desde 1998), Mestre (2000) e Doutor (2003) em Direito Constitucional pela UFPR com estudos de Doutoramento na Ludwig Maximilians Universität de Munique, Alemanha (2001-2003). Atualmente é Procurador Federal Chefe da Procuradoria Federal junto a Universidade Federal do Paraná. Professor Pesquisador de Direito Constitucional nos Cursos de Graduação e Pós-Graduação (Mestrado e Especialização) em Direito da UniBrasil e Professor Visitante de Direito Constitucional na Faculdade de Direito de Francisco Beltrão - Cesul. Ex-Bolsista do Deutscher Akademischer Austauschdienst - DAAD, do CNPq e da CAPES. É autor dos seguintes livros: Estado e Século XXI. A integração supranacional sob a ótica do Direito Constitucional (Rio de Janeiro: Renovar, 2006); O Direito à Educação e a Constituição (Porto Alegre: Fabris, 2001); Pluralismo Jurídico e Direito Moderno. Notas para pensar a racionalidade jurídica na modernidade (Curitiba: Juruá, 2000) e Introdução à Sociologia do Direito de Eugen Ehrlich (Curitiba: Juruá, 2001). Possui diversos artigos publicados em revistas especializadas. Endereço eletrônico: marcosmaliska@yahoo.com.br 


\section{INTRODUÇÃO}

O desenvolvimento das instituições sociais, econômicas e culturais nas sociedades ocidentais modernas foi desencadeado por um processo geral de racionalização. Max Weber (1864-1920) foi o autor que melhor trabalhou esse processo de racionalização, entendido como "o resultado da especialização científica e da diferenciação técnica peculiar à civilização ocidental. Consiste na organização da vida, por divisão e coordenação das diversas atividades, com base em um estudo preciso das relações entre os homens, com seus instrumentos e seu meio, com vistas à maior eficácia e rendimento. Trata-se, pois, de um puro desenvolvimento prático operado pelo gênio técnico do homem". ${ }^{1}$

São diversas as análises sobre o conceito de racionalidade e os sentidos que ele se apresenta na obra de Weber. ${ }^{2}$ De grande importância, mas que infelizmente esse trabalho não comporta analisar, é a recepção da teoria da racionalidade de Weber pelo marxismo, em especial na interpretação da racionalização como "coisificação" (Verdinglichung) por Lukács ${ }^{3}$ e na análise de Marcuse, para o qual a concepção weberiana de Racionalidade e Racionalização fornece uma visão neutra da pesquisa científica social e por isso atualmente de grande interesse ideológico para específicos interesses dominantes. ${ }^{4}$

\footnotetext{
${ }^{1}$ FREUND, Julien. Sociologia de Max Weber. Trad. Luís Cláudio de Castro e Costa. 2. ed. Rio de Janeiro: Forense, 1975, p. 19.

2 Assim, por exemplo, segundo Johannes Weiß, Weber fala de Racionalidade e Racionalização em no mínimo três sentidos, a saber no sentido da ciência empírica, da interpretação e da Ética. WEI $\beta$, Johannes. Max Webers Grundlegung der Soziologie. Eine Einführung. München: Verlag Dokumentation, 1975, p. 137. De outro modo, observa Reinhard Bendix que na obra de Weber a racionalidade se apresenta como (i) uma importante manifestação da liberdade individual, (ii) como sinônimo de clareza e (iii) como conduta de vida. (BENDIX, Reinhard. Max Weber: Das Werk. Darstellung, Analyse, Ergebnisse. Trad. do original em inglês para o alemão por Renate Rausch. München: Piper, 1960, p. 403).

${ }^{3}$ Ver BEIERSDÖRFER, Kurt. Max Weber und Georg Lukács. Über die Beziehung von Verstehender Soziologie und Westlichen Marxismus. Frankfurt am Main: Campus, 1986, p. 156.

${ }^{4}$ WEI $\beta$, Johannes. Das Werk Max Webers in der marxistischen Rezeption und Kritik. Opladen: Westdeutscher Verlag, 1981, p. 147. Ver também (Industrialisierung und Kapitalismus im Werk Max Webers In. MARCUSE, Herbert. Kultur und Gesellschaft. 4. ed. Frankfurt am Main:
} 
Habermas observa em Weber três tipos de racionalizações: a da sociedade, a cultural e a da personalidade. Weber conceitua igualmente a "modernização da sociedade" (Modernisierung der Gesellschaft) como Marx faz ao falar em "diferenciação" (Ausdifferenzierung) da Economia Capitalista e do Estado Moderno. Ambas completam-se assim em suas funções, estabilizando-se mutuamente. O núcleo organizativo da economia capitalista molda a empresa capitalista, entre outros aspectos, por uma contabilidade racional, pela introdução de uma eficiente e formal mão de obra livre, pela utilização do conhecimento técnico-científico e por decisões de investimento orientadas para o mercado. Por outro lado, o núcleo organizativo do Estado Moderno caracteriza-se, entre outros aspectos, por meio da introdução de um central e contínuo sistema tributário, um central comando militar, pelo monopólio do uso da violência e por uma administração burocrática. O meio de organização da economia capitalista e do Estado Moderno, como também as relações entre ambos, é realizado pelo princípio normativo assentado no direito formal. São esses três elementos, segundo Habermas, que constituem a racionalização da sociedade. A racionalização cultural, caracterizada pela previsibilidade, pelo cálculo e pelo controle organizativo e instrumental dos processos empíricos, é encontrada por Weber na moderna ciência e técnica, na arte e na religião autônomas guiadas por Princípios Éticos. Por fim, a racionalização da personalidade refere-se à conduta racional de vida (methodische Lebensführung), que é considerada o ponto de ligação entre as racionalizações cultural e social. ${ }^{5}$ A racionalização da personalidade significa, basicamente, "que não basta a constatação de fatores materiais, faz-se necessária uma internalização de valores e de idéias". 6

Segundo a análise de Karl Loewenstein, Weber foi um pensador que foi além

Suhrkamp, 1967, p. 107-129).

5 HABERMAS, Jürgen. Theorie des Kommunikativen Handelns. Frankfurt am Main: Suhrkamp, 1988. v. 1, p. 226 e 227.

${ }^{6}$ (ARGÜELlO, Katie. O Ícaro da modernidade. Direito e Política em Max Weber. São Paulo: Acadêmica, 1997, p. 70-71). No tocante a "internalização de valores e idéias", observa Volker Heins ao trabalhar a Racionalidade versus Conduta de Vida, que Max Weber, em sua vida privada, decidiu-se pela igualdade da Mulher, subordinado a racionalidade da moralidade do erotismo, ficando igualmente dividido pela nostalgia de um erotismo irresponsável. (HEINS, Volker. Max Weber. Zur 
do seu tempo e de sua geração ao ficar indiferente às clássicas ideologias da época (Capitalismo Liberal e Socialismo ou Estado Total Comunista e Fascismo). Para ele, a esperada socialização era um meio técnico de aperfeiçoamento da gerência empresarial do Estado, porém sem valor absoluto. ${ }^{7}$

De importância ao presente estudo é a sociologia política de Weber, em especial os seus estudos sobre o Estado Racional, as formas de legitimação do Poder e a questão da burocracia.

\section{O ESTADO RACIONAL}

Max Weber formou-se em Direito, mas desde logo sua mãe já observava que o filho interessava-se mais pelo desenvolvimento histórico do Direito à sua aplicação prática, pois, segundo ela, ele como um funcionário não era suficientemente prático e organizado para o trabalho burocrático diário. ${ }^{8}$ Após se decidir pela carreira acadêmica, Weber dedicou-se a estudar a sociedade burguesa ocidental em seus diversos aspectos, em especial através do resgate histórico dos diversos fatores que tiveram influência no seu desenvolvimento. Segundo Wolfgang Schluchter, o primeiro tema de Weber é o Capitalismo, relacionando-o, de início, com uma perspectiva histórica e como problema de organização. Já na sua primeira grande publicação, no estudo sobre a História das Companhias de Comércio nas cidades medievais italianas, ${ }^{9}$

Einführung. Hamburg: SOAK im Junius Verl., 1990, p. 22).

${ }^{7}$ LOEWENSTEIN, Karl. Max Webers staatspolitische Auffassungen in der Sicht unserer Zeit. Frankfurt am Main e Bonn: Athenäum Verlag, 1965, p. 18.

${ }^{8}$ Segundo KRÜGER, Christa. Max \& Marianne Weber. Tag und Nachtansichten einer Ehe. Zürich, München: Pendo, 2001, p. 20. Sobre o desenvolvimento intelectual de Weber, conforme relata Marianne Weber na biografia sobre o marido, vale mencionar o seu precoce interesse pela leitura em geral, em especial pelos clássicos. Aos doze anos Weber relatou a sua mãe que tinha se curvado ao Príncipe de Maquiavel e que leria sobre antimaquiavel e também lançaria uma olhada sobre a obra de Lutero. (WEBER, Marianne. Max Weber. Ein Lebensbild. Tübingen: Mohr e Siebeck, 1926, p. 48).

${ }^{9}$ WEBER, Max. Zur Geschichte der Handelsgesellschaften im Mittelalter. Stuttgart, 1889. 
encontra-se essa análise. ${ }^{10} \mathrm{Na}$ análise de Mommsen, os temas dominantes na obra sociológica de Weber são o crescimento do moderno Capitalismo industrial e o desenvolvimento social. Segundo Mommsen, Weber prognosticou, já em 1893, que o capitalismo dentro de poucas gerações destruiria todas as formas tradicionais de estruturas sociais e a estrutura social tradicional não seria reintroduzida. Para Weber o moderno Capitalismo seria um poder revolucionário mau (schlechthin revolutionäre Macht). ${ }^{11}$

Neste cenário, o estudo que Weber realizou sobre o Estado é todo permeado, em especial, por considerações acerca da política, da história e da economia. Segundo escreve Katie Argüello, pode-se afirmar que existe um "nexo de dependência causal" entre as várias dimensões da estrutura social, ou seja, "de uma ética religiosa racionalizada, da organização administrativa fundada no cálculo racional, do direito racional-formal, do Estado Moderno, depende o capitalismo racional moderno e viceversa". ${ }^{12}$

Reinhard Bendix apresenta quatro características para uma comunidade política ter a existência do Estado Moderno, segundo a teoria de Weber: i) uma administração e uma ordem jurídica, na qual as alterações se dão por normas; ii) uma administração militar, na qual os seus serviços realizam-se em concordância com rigorosos deveres e direitos; iii) monopólio de Poder sobre todas as pessoas, tanto sobre as que nasceram na comunidade quanto aquelas que estão nos domínios do território; iv) legitimação da aplicação do Poder nos limites do território por concordância com a ordem jurídica. ${ }^{13}$

${ }^{10}$ SCHLUCHTER, Wolfgang. Die Entwicklung des okzidentalen Rationalismus. Eine Analyse von Max Webers Gesellschaftsgeschichte. Tübingen: Mohr e Siebeck, 1979, p. 15.

${ }^{11}$ MOMMSEN, Wolfgang. Max Weber. Gesellschaft, Politik und Geschichte. Frankfurt am Main: Suhrkamp, 1974, p. 144.

${ }^{12}$ ARGÜELLO, op. cit., p. 83. Essa posição é tomada também por Volker Heins, quando escreve que, por um lado, as formas de domínio político possuem também o status de forças de esclarecimento (erklärungskräftigen) das condições de formação do processo religioso e do modo inverso também da necessidade de esclarecimento da estrutura política, em especial da força participativa da Religião Cristã no surgimento dos Estados Ocidentais. (HEINS, op. cit., p. 47).

${ }^{13}$ BENDIX, op. cit., p. 317. 
Identificado como o Estado racional, o Estado Moderno Ocidental, segundo Weber, diferenciou-se de outras formas estatais, como as de base patriarcal e patrimonial. É sob a égide de um Estado racional pautado em um direito racional e em uma burocracia profissional é que irá se assentar o desenvolvimento do capitalismo moderno. ${ }^{14}$ Weber anota também que no Estado Moderno foi decisivo o apoio dos juristas, pois segundo ele, contrário ao Império Chinês em que o Monarca não tinha juristas a sua disposição, no Ocidente encontrou-se disponível um direito formal, produto do gênio romano, no qual os funcionários, como técnicos administrativos, tinham o Direito como superior a tudo. ${ }^{15}$ Essa racionalidade que permeou o agir da burocracia estatal moderna possibilitou os mecanismos necessários para o desenvolvimento capitalista. Weber lembra que na antiga China, um homem que vendesse sua casa e que algum tempo depois ficasse pobre, segundo o antigo mandamento chinês da ajuda mútua (Bruderhilfe), tinha o direito de retornar para a casa e nela permanecer como "Locatário forçado" (Zwangsmieter), sem pagar aluguel. Com um tal direito, observa Weber, o capitalismo não teria como funcionar economicamente. $^{16}$

Para Weber, o Estado, sociologicamente, só se deixa definir pelo meio especifico que the é peculiar, tal como é peculiar a todo outro agrupamento político, ou seja, o uso da coação física. ${ }^{17}$ Em outras palavras, o Estado define-se como a estrutura ou o agrupamento político que reivindica, com êxito, o monopólio do constrangimento físico legítimo. A esse caráter específico do Estado, acrescentam-se outros traços: de um lado, comporta uma racionalização do Direito com as conseqüências que são a especialização dos poderes legislativo e judiciário, bem como a instituição de uma polícia encarregada de proteger a segurança dos indivíduos e de assegurar a ordem pública; de outro lado, apóia-se em uma administração racional baseada em

${ }^{14}$ Wirtschaft und Gesellschaft. Grundriss der Verstehenden Soziologie. 5. ed. Tübingen: Mohr Siebeck, 1980, p. 815.

${ }^{15}$ Ibid., p. 817.

${ }^{16}$ Ibid., loc. cit.

${ }^{17}$ Politik als Beruf. Gesammelte Politische Schriften. 5. ed. Tübingen: Mohr Siebeck, 1988, p. 506. 
regulamentos explícitos que lhe permitem intervir nos domínios os mais diversos, desde a educação até a saúde, a economia e mesmo a cultura. Enfim, dispõe de uma força militar, por assim dizer, permanente. ${ }^{18}$

Citando uma frase de Trotsky: "todo Estado se funda na força", Weber observa que se só existissem estruturas sociais das quais a violência estivesse ausente, o conceito de Estado teria também desaparecido e apenas subsistiria o que, no sentido próprio da palavra, se denomina "anarquia". A violência não é, evidentemente, o único instrumento de que se vale o Estado - não haja a respeito qualquer dúvida -, mas é seu instrumento especifico. Em nossos dias, a relação entre o Estado e a violência é particularmente íntima. Em todos os tempos, os agrupamentos políticos mais diversos - a começar pela família - recorreram à violência física, tendo-a como instrumento normal do poder. Em nossa época, entretanto, deve-se conceber o Estado contemporâneo como uma comunidade humana que, dentro dos limites de determinado território - a noção de território corresponde a um dos elementos essenciais do Estado - reivindica o monopólio do uso legítimo da violência física. E, com efeito, é próprio de nossa época o não reconhecer, em relação a qualquer outro grupo ou aos indivíduos, o direito de fazer uso da violência, a não ser nos casos em que o Estado a tolere: o Estado se transforma, portanto, na única fonte do "direito" à violência. $^{19}$

O agrupamento político, ou seja, o Estado, é um agrupamento de domínio (Herrschaft). O domínio em geral, como conceito sem conteúdo concreto, é um importante elemento das relações sociais. $\mathrm{Na}$ verdade, nem todas as relações sociais apresentam-se como estruturas de domínio, mas, no entanto, tem ele, para a maioria delas, uma elevada importância. ${ }^{20} \mathrm{O}$ domínio é uma forma especial de Poder (Macht). O domínio, no sentido geral do Poder, assim como a possibilidade de uma vontade de se impor em relação à outra, pode se apresentar de diferentes formas. ${ }^{21}$ Segundo Julien

\footnotetext{
${ }^{18}$ FREUND, op. cit., p. 159.

${ }^{19}$ WEBER, Max. Politik als Beruf ..., p. 506.

${ }^{20}$ WEBER, Max. Wirtschaft und Gesellschaft..., p. 541.

${ }^{21}$ Ibid., p. 542.
} 
Freund, o conceito de poderio (Macht) se caracteriza pela oportunidade de um indivíduo de fazer triunfar, no seio de uma relação social, sua própria vontade contra resistências, e o conceito de domínio como a oportunidade de aí encontrar pessoas dispostas a obedecer às ordens que lhe são dadas. ${ }^{22}$ Segundo Weber, o verdadeiro domínio encontra-se no Estado Moderno, o qual não se realiza no discurso parlamentar, nem nas Enunciações do Monarca, senão na aplicação diária da Administração, necessária e inevitavelmente nas mãos do funcionalismo (Beamtentums), seja militar ou civil. ${ }^{23}$

\section{AS TRÊS FORMAS DE LEGITIMAÇÃO DO PODER}

Ao tratar da legitimidade do poder, ${ }^{24}$ Weber, em sua Sociologia Política, distingue três tipos de dominação legítima: a tradicional, a carismática e a racional legal. Deve-se registrar que Weber, quando trata dos tipos de dominação, deixa claro que se tratam de tipos-ideais, ${ }^{25}$ e, por conseguinte, que nunca se encontram, ou só muito raramente, em estado puro na realidade histórica. ${ }^{26}$ Segundo Weber, para a

\footnotetext{
${ }^{22}$ FREUND, op. cit., p. 160-161.
}

${ }^{23}$ WEBER, Max. Wirtschaft und Gesellschaft..., p. 825.

24 "A legitimidade, na sua condição de categoria da teoria política, tem sido compreendida como uma relação de correspondência entre algo e seus destinatários, sob um aporte axiológico, portanto, ressaltando os valores em questão numa relação de poder". (PASOLD, Cesar Luiz. Reflexões sobre o poder e o direito. Florianópolis: Estudantil, 1986, p. 20).

${ }^{25}$ A categoria do tipo ideal é a ponte que liga o componente subjetivo nas ciências da cultura com o conhecimento estritamente empírico. O tipo ideal é o principal meio metodológico tanto para estabelecer o significado cultural dos fenômenos, quanto para formular proposições empíricas sobre eles. O conceito de tipo ideal é obtido pelo realce unilateral de um ou de vários pontos de vista e a reunião de uma multidão de fenômenos singulares, difusos e discretos que se encaixam naqueles pontos de vista dentro do quadro conceptual em si unitário. Essa unidade conceptual é o que confere ao tipo ideal a univocidade que permite a objetividade na comparação de vários fenômenos do mesmo tipo. O tipo ideal é o modo de construção de conceitos peculiar ao método histórico ou individualizante, cujo sabemos que é o estudo da realidade e dos fenômenos em sua singularidade. Ver: SAINT-PIERRE, Héctor L. Max Weber. Entre a Paixão e a Razão. Campinas: Unicamp, 1994, p. 67-83.

26 "[...] o domínio carismático, por exemplo, não é inteiramente desprovido de legalidade, e a 
pesquisa científica, o conceito de tipo-ideal pretende instruir a decisão: ele não é hipótese, porém ele quer indicar a direção da formação hipotética. Ele não é representação do real, porém ele quer proporcionar, claramente, um meio de expressão da representação. ${ }^{27}$

Dentre as formas de legitimação do poder, o domínio tradicional tem por base a crença na santidade das tradições em vigor e na legitimidade dos que são chamados ao poder em virtude do costume. A autoridade não pertence a um superior escolhido pelos habitantes do país, mas sim a um homem que é chamado ao poder em virtude de um costume (primogenitura, por exemplo). Ele reina a título pessoal, de sorte que a obediência se dirige à sua pessoa e se torna um ato de piedade. Os governados são súditos que não obedecem a uma norma impessoal, mas ordens legitimadas em virtude do privilégio tradicional do soberano. Segundo o humor deste, podem-se obter seus favores ou cair em desgraça. No entanto, a tradição não é assimilável ao puro arbítrio, pois se o soberano a viola, arrisca-se a provocar uma resistência que, certamente, não visa ao sistema, mas sim a sua pessoa ou a seus favoritos. ${ }^{28}$

O domínio carismático, de outro modo, repousa no valor pessoal de um homem que se distingue por sua santidade, seu heroísmo ou seus exemplos. Constitui o tipo excepcional do poderio político, não pelo fato de se encontrar raramente, mas porque deturpa os usos da vida política ordinária. Weber entende por carisma a qualidade insólita de uma pessoa que parece dar provas de um poder sobrenatural, sobre-humano ou pelo menos desusado, de sorte que ela aparece como um ser providencial, exemplar, ou fora do comum e, por essa razão, agrupa em torno de si discípulos ou partidários. O comportamento carismático não é peculiar apenas à atividade política, pois pode ser igualmente observado em outros campos, como os da religião, da arte, da moral e mesmo da economia, conquanto, segundo Weber, um dos traços do carisma consista em permanecer estranho ou hostil ao jogo econômico

tradição encerra certos aspectos carismáticos ou mesmo burocráticos". (FREUND, op. cit., p. 167).

${ }^{27}$ WEBER, Max. Methodologische Schriften. Frankfurt am Main: S. Fischer Verlag, 1968, p. 42.

${ }^{28}$ FREUND, op. cit., p.168 e WEBER, Max. Wirtschaft und Gesellschaft ..., p. 130, 131. 
normal. Em política, este domínio toma diversas formas: a do demagogo, do ditador social, do herói militar ou do revolucionário. ${ }^{29}$

Segundo Stefan Breuer, em seu livro Bürokratie und Charisma, Weber não

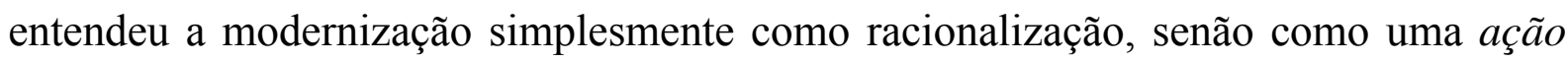
recíproca (Wechselwirkung) (segundo o autor, falar em Dialética seria exagero) de racionalidade e carisma. Partindo disso, aborda o autor, por exemplo, o Carisma da Razão, entendido como expressão de um Carisma impessoal, e o Carisma da Nação, presente em vários momentos da história, com na França de 1789 ou na Alemanha de $19144^{30}$

Por fim, o domínio racional legal, típico do Estado Moderno, tem por fundamento a crença na validade dos regulamentos estabelecidos racionalmente e na legitimidade dos chefes designados nos temos da lei. Neste sentido, todo direito, seja ele estabelecido por convenção ou por outorga, vale em virtude de um procedimento racional. O conjunto das regras de direito constitui um mundo abstrato de prescrições técnicas ou de normas, em que compete à Justiça a aplicação das regras gerais aos casos particulares, enquanto a administração tem por objeto proteger os interesses nos limites das regras de direito, graças a órgãos instituídos para tal fim. O chefe legal e as instâncias superiores, inclusive o Presidente da República eleito, devem respeitar a ordem impessoal do direito e se orientar segundo a mesma. Os membros do agrupamento só obedecem ao direito e são chamados cidadãos, isto quer dizer que não são obrigados a submeter-se senão nas condições previstas pela lei. ${ }^{31}$

O domínio racional legal consiste em um empreendimento contínuo de funções públicas instituídas por leis e distribuídas em competências diferenciadas. A aplicação desses inúmeros regulamentos exige uma equipe de funcionários qualificados, que não são donos de seus cargos, nem tampouco dos meios da administração. Por outro lado, são protegidos, no exercício de suas funções, por um

\footnotetext{
${ }^{29}$ FREUND, op. cit., p.169 e WEBER, Max. Wirtschaft und Gesellschaft..., p. 140 e seg.

${ }^{30}$ BREUER, Stefan. Bürokratie und Charisma. Zur politischen Soziologie Max Webers. Darmstadt: Wissenschaftliche Buchgesellschaft, 1994, p. 2, 59, 110, 111.

${ }^{31}$ WEBER, Max. Wirtschaft und Gesellschaft ..., p. 125.
} 
estatuto. O procedimento administrativo repousa no princípio de documentos e fichários a serem conservados: todas as decisões, decretos e ordens de serviço são escritos. A mais típica forma do domínio racional legal é a burocracia. ${ }^{32}$

\section{A BUROCRACIA}

O domínio racional legal se expressa através da burocracia. Entendida como o governo da razão, ${ }^{33}$ a burocracia é o meio através do qual se expressa a lei e sob o qual age o Estado Racional Moderno. A burocracia é, portanto, um produto histórico peculiar e inevitável do desenvolvimento da racionalidade formal no Estado Moderno. Segundo anota Katie Argüello, "o objetivo da burocracia é o de gerir o poder. Esta gestão, por sua vez, pode ser mais racional, quando mediada pelo tipo de administração burocrática pura, (administração burocrático-monocrático), que ressalta os aspectos da precisão, disciplina, continuidade, calculabilidade, aperfeiçoamento técnico, enfim, de eficácia. Em termos históricos concretos, essa instrumentalidade do agir racional com relação aos fins diz respeito à função da força política do Estado moderno desenvolvido no Ocidente". ${ }^{34}$

Ao questionar qual é o entendimento de Weber sobre Burocracia, Arnold Zingerle observa que Weber não apresenta em nenhum lugar uma definição de burocracia, senão que apresenta ele a burocracia como um modo de administração (administração através e em uma organização de Escritórios) sobre uma característica coletiva de pessoas que são representantes de tal administração, até a caracterização dessa relação como domínio (domínio através da burocracia). ${ }^{35}$

\footnotetext{
${ }^{32}$ FREUND, op. cit., p. 167.

${ }^{33}$ BINS, Milton. Introdução à sociologia geral. Porto Alegre: Mundo Jovem, 1985, p. 37.

${ }^{34}$ ARGÜELLO, op. cit., p. 82-83.

${ }^{35}$ ZINGERLE, Arnold. Max Webers Historische Soziologie. Aspekte und Materialien zur
} Wirkungsgeschichte. Darmstadt: Wissenschaftliche Buchgesellschaft, 1981, p. 113. 
Como características gerais da burocracia têm-se que as atribuições dos empregados são fixas, definidas. No mando os poderes são distribuídos de forma clara e delimitada e, na execução, cada um tem tarefas definidas. Num e noutro caso as responsabilidades são específicas. Existe um sistema organizado de mando e subordinação. As autoridades superiores inspecionam as inferiores, podendo estas apenas apelar. O mando é vertical e descendente, sendo a forma hierárquica mais desenvolvida aquela em que no topo da pirâmide há uma só pessoa (monocracia). A Administração é baseada em documentos. Para efeitos da administração, só tem existência eficaz o assunto registrado por escrito. Ocorre uma nítida separação entre as atividades burocráticas e as atividades pessoais dos empregados, bem como entre os bens da administração e os bens pessoais dos empregados. Os empregados são protegidos mediante um estatuto e mediante a garantia de uma remuneração regular em dinheiro. O recrutamento para ocupação das vagas existentes se dá por meio de provas e diplomas. ${ }^{36}$

As burocracias reais divergem consideravelmente do tipo-puro descrito por Weber, sendo as organizações administrativas estatais as que possuem o maior grau de desvio em relação ao modelo abstrato definido. Dentre as causas para tal desvio, observa Milton Bins, que existe o mito de que a administração (pública) pode ser separada da política. Os partidos políticos e outros grupos de interesse disputam avidamente os cargos públicos em razão dos vastos recursos de poder que os mesmos propiciam. Os costumes tradicionais - o paternalismo, o nepotismo, o clientelismo etc., costumam adentrar às organizações. Não há distinção nítida entre os bens públicos e os bens privados, tornando-se, o cargo - de alto a baixo na hierarquia fonte de lucro pessoal e de toda sorte de outras corrupções. Por fim, existe a incompetência pura e simples e a acomodação. ${ }^{37}$

\footnotetext{
${ }^{36}$ WEBER, Max. Wirtschaft und Gesellschaft ..., p. 126-127.

${ }^{37}$ BINS, op. cit., p. 41.
} 


\section{REFERÊNCIAS}

ARGÜELLO, Katie. O Ícaro da modernidade. Direito e política em Max Weber. São Paulo: Acadêmica, 1997.

BEIERSDÖRFER, Kurt. Max Weber und Georg Lukács. Über die Beziehung von Verstehender Soziologie und Westlichen Marxismus. Frankfurt am Main: Campus, 1986.

BENDIX, Reinhard. Max Weber: Das Werk. Darstellung, Analyse, Ergebnisse. Trad. do original em inglês para o alemão por Renate Rausch. München: Piper, 1960.

BINS, Milton. Introdução à sociologia geral. Porto Alegre: Mundo Jovem, 1985.

BREUER, Stefan. Bürokratie und Charisma. Zur politischen Soziologie Max Webers. Darmstadt: Wissenschaftliche Buchgesellschaft, 1994.

FREUND, Julien. Sociologia de Max Weber. Trad. Luís Cláudio de Castro e Costa. 2. ed. Rio de Janeiro: Forense, 1975.

HABERMAS, Jürgen. Theorie des Kommunikativen Handelns. Frankfurt am Main: Suhrkamp, 1988. v. 1.

HEINS, Volker. Max Weber. Zur Einführung. Hamburg: SOAK im Junius Verl., 1990.

KRÜGER, Christa. Max \& Marianne Weber. Tag und Nachtansichten einer Ehe. Zürich, München: Pendo, 2001.

LOEWENSTEIN, Karl. Max Webers staatspolitische Auffassungen in der Sicht unserer Zeit. Frankfurt am Main e Bonn: Athenäum Verlag, 1965.

MOMMSEN, Wolfgang. Max Weber. Gesellschaft, Politik und Geschichte. Frankfurt am Main: Suhrkamp, 1974.

MARCUSE, Herbert. Kultur und Gesellschaft. 4. ed. Frankfurt am Main: Suhrkamp, 1967.

PASOLD, Cesar Luiz. Reflexões sobre o poder e o direito. Florianópolis: Estudantil, 1986.

SAINT-PIERRE, Héctor L. Max Weber. Entre a Paixão e a Razão. Campinas: Unicamp, 1994.

SCHLUCHTER, Wolfgang. Die Entwicklung des okzidentalen Rationalismus. Eine Analyse von Max Webers Gesellschaftsgeschichte. Tübingen: Mohr e Siebeck, 1979.

WEBER, Marianne. Max Weber. Ein Lebensbild. Tübingen: Mohr e Siebeck, 1926. 
WEBER, Max. Zur Geschichte der Handelsgesellschaften im Mittelalter. Stuttgart, 1889.

. Wirtschaft und Gesellschaft. Grundriss der Verstehenden Soziologie. 5. ed. Tübingen: Mohr Siebeck, 1980.

. Politik als Beruf. Gesammelte Politische Schriften. 5. ed. Tübingen: Mohr Siebeck, 1988.

. Methodologische Schriften. Frankfurt am Main: S. Fischer Verlag, 1968.

WEI $\beta$, Johannes. Max Webers Grundlegung der Soziologie. Eine Einführung. München: Verlag Dokumentation, 1975.

. Das Werk Max Webers in der marxistischen Rezeption und Kritik. Opladen: Westdeutscher Verlag, 1981.

ZINGERLE, Arnold. Max Webers Historische Soziologie. Aspekte und Materialien zur Wirkungsgeschichte. Darmstadt: Wissenschaftliche Buchgesellschaft, 1981. 